\title{
Mappevurdering i matematikk: Framsteg eller naudsynt onde?
}

\author{
Hans Georg Schaathun*1 \\ ${ }^{1}$ NTNU - Noregs Teknisk-Naturvitskaplege Universitet
}

\begin{abstract}
Pandemien har i 2020 tvunge mange matematikkførelesarar til å bruka mappevurdering og heimeeksamen i staden for dei tradisjonelle skuleeksamenane med streng kontroll på hjelpemiddel. Dette er kontroverielt når eksamen skal testa rekneferdigheiter. I denne artikkelen vil me vri spørsmålet og sjå på kva matematikkompetansar me kan vurdera gjennom mappeeksamen, og foreslå eit mappevurderingsdesign som dekkjer viktige læringsutbyte som ofte ikkje vert prøvde på eksamen.
\end{abstract}

\section{INNLEIING}

Matematikkundervisinga har sterke tradisjonar, og mange har sterke førestillingar om kva matematikkeksamen inneber. Studentane viser at dei kan rekna gjennom skriftleg skuleeksamen med streng kontroll på hjelpemiddel. Dette har vore umogleg å gjennomføra med smittevernregimet i 2020, og alternative løysingar har tvunge seg fram, til tross for at ein vanskeleg kan prøva dei same ferdigheitene utan den strenge kontrollen som ein har i eit eksamenslokale.

Ved MNT-konferansen 2019 stilte me (Schaathun og Moe, 2019) spørsmål om kva som eigentleg er målet i matematikken, og me identifiserte fleire mål som ofte er identifiserte i emneskildringa, men som sjelden vert prøvde på eksamen. Den gongen hadde me derimot ikkje noka ferdig løysing på korleis me kunne vurdera desse læringsmåla, og tida var heller ikkje moden for å utfordra det etablerte eksamensregimet. Idéen om nye vurderingsformar vart bråmoden med smittevernsregimet, og i 2020 me kunne innføra mappevurdering utan særleg diskusjon. På papiret er mappevurdering ei naudløysing, men i røynda er det eit eksperiment.

I denne artikkelen skal me fyrste presentera emnedesignet slik som det var i 2019, og dernest den nye vurderingsmodellen frå 2020. Me går so systematisk igjennom dei observasjonene og lærdomane som er gjort. Me kan berre gje ei førebels evaluering her. Sensuren er so vidt avslutta, og me skal gå gjennom røynslene saman med referansegruppa. Resultata derifrå vert presenterte på konferansen. Arbeidet er eit steg i ein langvarig, iterative design-prosessen, og Schaathun og Moe (sst.) skriv meir utførleg om metodikken.

\section{EMNEDESIGN 2019}

Matematisk Problemløysing inngår i fleire studieprogram på lågare grad. Målgruppa er studentar som ikkje har fordjuping i matematikk frå vidaregåande skule, og emnet er eit alternativ for dei som ikkje ynskjer å ta matematikkurset som inngår i siviløkonomstudiet og byggjer på S2 (full fordjuping i samfunnsvitskapleg matematikk). Dette gjer at emnet ikkje er bunde av nokon rammeplan og me har stått fritt til å utforma emnet til målgruppa. Me skal likevel presisera at dei læringsutbyta som me fokuserer på her, ikkje er særeigne. Me finn liknande læringsutbyte i mange andre matematikkemne.

Då forfattaren overtok ansvaret for emnet i 2017, var hovudfokuset å læra studentane å løysa abstrakte problem, som t.d. det i tabell 1. Slike oppgåver løyser me gjerne med velkjende prosedyrar som lett lèt seg implementera på datamaskiner. Studentane vert dermed prøvde på problem som dei aldri treng løysa i framtida, fordi datamaskiner gjer det betre. Studentane på ulike profesjonsstudium skal lesa matematikk som eit verkty for å forstå røynda. Då treng dei ei rekkje andre matematikkompetansar (t.d. Niss og Højgaard, 2011). I Matematisk Problemløysing ${ }^{1}$ skal kandidatene m.a.

\footnotetext{
*hasc@ntnu.no

${ }^{1}$ Fullstendig emneskildring: https ://www .ntnu.no/studier/emner/AR101015\#tab=omEmnet.
} 


\section{Oppgave 3}

En funksjon $f$ er gitt ved $f(x)=2 x^{3}-18 x^{2}+30 x+1$.

a) Bestem $f^{\prime}(x)$, den deriverte til $f(x)$.

b) Bestem $x$-verdien til topp- og bunnpunkt for $f$-grafen. Avgjør hvilken $x$-verdi som gir topp- henholdsvis bunnpunkt.

c) Bestem skjæringspunktet mellom $x$-aksen og den rette linjen som tangerer $f$-grafen i punktet $(0, f(0))$.

Tabell 1: Ei oppgåve frå eksamen 2015.

- kunna sjå samanhengen mellom abstrakte matematiske modellar og konkrete problem i bedriftsøkonomi og marknadsanalyse.

- kunna kommunisera om og ved hjelp av matematikk.

- kunna matematisera, dvs. finna løysbare matematiske formuleringar for problem frå røynda.

Alle desse kompetansane inngår i ein typisk arbeidsprosess. Fyrst må ein tolka røynda (matematisera), for å finna ein løysbar matematisk modell. Når utrekningane er gjort må abstrakta resultat omsetjast til det konkrete problemet. Til slutt skal ein bruka resultata til å fremja ein foretningsplan eller eit design, og ein må då kunna kommunisera slik at kollegaane vert overtydde. Sjølv om rekneferdigheitene kan vera viktige, og det er mogleg å pugga dei, vil mekanisk pugg føra til at ferdigheitene vert «isolerte kunnskapsenheter» (Holm, 2012, s. 44). Då vil dei heller ikkje fungera i den problemløysingsprosessen der våre studentar vil trengja dei. Det har me òg observert på tidlegare eksamenar (Schaathun og Moe, 2019).

Matematisk Problemløysing fokuserer på å setja alle rekneferdigheitene i ein meiningsfull kontekst. Eit eige oppgåvesett er utvikla til emnet, basert på parra døme (Clark, Nguyen og Sweller, 2005). Kvart par består av ei oppgåve med utførleg løysingsforslag som innfører ein ny teknikk eller eit konsept, og ei påfylgjande, liknande oppgåve utan løysingsforslag. Fleirtalet av oppgåver er bygd opp som praktiske problem som må tolkast før dei kan løysast, og dei abstrakte oppgåvene fokuserer på heilskap og samanheng (t.d. tabell 2). Kvar økt, på fire timar, startar og sluttar med éin time førelesing (briefing og debrief). Dei to timane i midten er rekneøving under vegleiing, der studentane vert oppmoda til gruppearbeid.

Firetimarsøktene har gjeve auka oppslutnad om rekneøvingane, der dei som kjem på briefing stort sett òg kjem på rekneøving. Mange studentar har rapportert at øvingsopplegget, med praktiske oppgåver, har gjort matematikken meiningsfull. Gruppearbeidet har vist at der er fleire måtar å løysa ting på, og for mange studentar er det ein aha-oppleving.

Me har lagt stor vekt på at feil er ein uunnværleg del av løysingsprosessen (Boaler, 2015). Det er tydeleg at mange studentar trur at ein skal kunna sjå på eit problem og raskt velja rett formel (sjå òg Piercey og Militzer, 2017, som siterer Muis 2004). Dersom dei ikkje ser løysinga med ein gong, gissar dei. Målet vårt har vore at studentane fyrst og framst skal forstå problemet i ein konkret kontekst. Gjennom å ta seg tid til å tolka problemet kan ein finna ein meiningsfull matematisk modell.

Ein annan kjepphest i emnet er at studentane må læra å validera eigne svar. Det er ein kjend sak i literaturen at mange studentar ikkje veit om dei har rett svar før dei ser i fasit. Dvs. at svaret ikkje er ein meiningsfull sanning for studenten, men ein løyndom som læraren definerer. Difor har øvingsheftet stort sett ikkje fasit, til store protestar frå svært mange studentar, men denne politikken har i alle fall skapt fokus på problemet. I yrkeslivet finst ingen fasit. Då må ein kunna stola på eigne utrekningar når ein skal velja foretningsplan.

Eksamen 2019 var ein ordinær skriftleg eksamen. Kjernepensumet (75-80\% av eksamen) utgjer eit lite repertoir av svært forutseielege oppgåver. Desse oppgåvene legg, som øvingsheftet. større vekt på heilskapstenking og på praktiske problem enn eksamen 2014-2016. Tabell 2 gjev eit døme. Det er rett nok 
Oppgåve 1. (25\%) Drøft og skissér funksjonen

$$
f(x)=2 x^{3}-6 x^{2}+4 x .
$$

Svar på fylgjande spørsmål, og markér svaret både i skissa og i teksta.

- Kva nullpunkt har funksjonen?

- Kva ekstremalpunkt (maksimum og minimum) har funksjonen? Bestem $x$ - og $y$-verdiane til ekstremalpunkta.

- For kva $x$-verdiar er funksjonen stigande?

- Finn vendepunktet til $f(x)$. Vis både $x$ - og $y$-verdien.

- Finn likninga for vendetangenten og teikn vendetangenten i skissa.

- Kva skjer med funksjonsverdien $f(x)$ når $x \rightarrow \infty$ ?

Tabell 2: Ei oppgåve frå eksamen 2019.

ikkje eit problem frå røynda, men viser ei heilskapstenking som ikkje tidlegare vart prøvd. Underspørsmåla liknar oppgåva frå 2015, men kravet om skisse er nytt. Det som me ser på eksamen er at svært mange av dei som kan rekna feilfritt på underspørsmåla, teiknar ei skisse som ikkje er konsistent med utrekningane. Studentane kan dermed visa rekneferdigheiter utan at svara dei får er meiningsfulle.

Trass alle endringane som me har gjort, vert skriftleg eksamen stadig ein forutseieleg øving der ein kan få ein middels god karakter ved å pugga eit lite utval oppgåvetypar. Fleire studentar enn før viser på eksamen at dei har dei rekneferdigheitene som dei treng, men der er inga endring å spora i korleis dei godtgjer svara sine. Dei aller fleste hoppar direkte på ein formel utan å forklara kvifor formelen er ein god modell for det praktiske problemet.

\section{MAPPEVURDERING 2020}

Det er typisk for kompetansemål at me ikkje kan forklara studentane korleis dei skal gjera det, i alle fall ikkje fullt ut. Studentane treng taus kunnskap for å forstå problemet. Forklaringar kan skrivast ned og takast fram når ein treng dei. Det er noko evigvarande ved dei, og det er som regel greitt å kopiera dei same forklaringane. Forståing handlar derimot om danning, heller enn utdanning, og danningsinnhaldet er er i konstant utvikling Kemp (2013). Både Kemp (sst.) og Schön (1987) peiker på kreativ imitasjon som vegen til å læra å forstå. Læresveinen imiterer tankesettet åt meisteren, men tolkar det på nytt for å forstå nye situasjonar. Som yrkesutøvar står ein overfor unike problem (Schön, 1983). Det nyttar ikkje å kopiera lærarens teknikk frå eit anna problem, men ein kan imitera tankesettet og bruka det for å finna nye løysingar i nye situasjonar.

Skriftleg eksamen, med sitt rigide format og korte tidsramme, tvingar i praksis studentane til å kopiera løysingsmetodar. Unike kompetansar vert ikkje verdsette uansett kor relevante og verdifulle dei er. Mappeformatet $^{2}$ vårt er inspirert av Carl Rogers klassiske Freedom to Learn (Rogers og Freiberg, 1994, kap. 3). Tittelen gjev hovudpoenget. Mappa skal gje studentane fridom til å visa det dei har lært på ein måte og i ein kontekst som er meiningsfull for dei. Me vil for all del unngå å tvinga dei inn i eit format der dei kopierer læraren. Kandidaten har sjølv ansvaret for å setja saman mappa for å dokumentera eiga læring i emnet i forhold til læringsutbyta i emneskildringa. Dette gjer dei delvis gjennom eit refleksjonsnotat (maks fem sider) og delvis gjennom eit utval oppgåver.

Formatet for mappa vart førelagt ekstern sensor og kunngjort ved semesterstart. Berre klargjerande justeringar vart gjort seinare, og då basert på diskusjon med studentane. Dermed skulle studentane kunna arbeida systematisk gjennom semesteret for å dokumentera eiga læring. I refleksjonsnotatet skulle studentane ta stilling til kva karakter dei har oppnådd, i forhold til læringsutbyta i emneskildringa og karakterdefinisjonan gjengjevne i tabell 3. Læringsutbyta er delt i skal-mål og bør-mål, der skal-måla er naudsynte til ein $\mathrm{E}$ og tilstrekkeleg til ein $\mathrm{C}$.

Bruken av refleksjonsnotat gjer det vanskeleg å kopiera andre. Kandidaten må dokumentera sitt eige forhold til matematikk, og plagiat vert openbert. Samstundes er oppgåveløysing ein del av dokumentasjonen,

\footnotetext{
${ }^{2}$ Heile emneopplegget ligg ope på http://www.hg.schaathun.net/math/mp12020/.
} 
E tyder at studenten har fått eit visst utbytte frå kvart av dei 3-4 hovudtemaa, men neppe kan nok til å bruka matematikken vidare i studiet utan at det krev ekstrainnsats. Mappa dekkjer alle dei fire hovudtemaa i pensum, med svar på nokre av dei mest avanserte oppgåvene, men treng ikkje inkludera korsmerkte oppgåver. Studenten viser at han ser samanhengen mellom problem frå røynda og den matematiske representasjonen som me bruker for å løysa dei. Forståinga har eit visst personleg preg der matematikken vert forstått ut frå eigen røysnler og vyar.

C skal tyda at studenten kan nok til å bruka matematikken i resten av studiet. Mappa skal då ha gode og fullstendige svar på nokre av dei mest samansette oppgåven. Normalt er der nokre korsmerkte oppgåver tekne med. Studenten har ikkje alltid lært eit vidt spektrum av matematiske teknikkar, men dei mest sentrale teknikkane har han gjort til sine eigne. Matematikken er gjort meiningsfull i ein samanheng som er viktig for studenten sjølv.

A tyder at studenten overraskar. Han tek i bruk teknikkar frå emnet på nye problem som ikkje er diskutert og løyser oppgåver eller oppgåvevariantar som ingen andre har løyst. Fleire av dei mest avanserte teknikkane som er gjennomgått i øvingane (dvs. korsmerkte oppgåver) er demonstrerte. Refleksjonen er grundig, personleg og balansert. Oppgåvesvara er grundige og feilfrie, og samanhengen mellom det praktiske problemet og den matematiske metoden er tydeleggjort.

$\mathbf{B}$ og $\mathbf{D}$ vert brukte når mappa har vesentlege drag frå både høgare og lågare karakterar.

F (stryk) tyder at studenten ikkje har dekt heile breidda av læringsutbyte i emnet. Dette er tilfellet dersom ikkje alle tema er dekte, eller dersom berre dei enklaste, innleiiande oppgåvene er inkludert. Det er òg tilfellet når oppgåvene i matematisk form er perfekt løyste, men tolkinga i den konkrete og praktiske situasjonen manglar. Mapper utan refleksjon, eller der refleksjonen er upersonleg og overdrive generell, får òg $\mathrm{F}$.

Tabell 3: Karakterdefinisjonar 2020.

slik det er svært vanskeleg å skriva mappe utan å ha ein viss, funksjonell matematisk forståing. Ved at mappearbeidet går over heile semesteret, skulle der òg vera tid til å gjera seg flid både med oppgåvetolking, presentasjon, validering og argumentasjon.

\section{LARDOMMEN FRÅ FYRSTE FORSØK}

Mot slutten av undervisingsperioden, då studentane tok til å arbeida seriøst med mappa, vart det tydeleg at mappa er ei krevjande oppgåve. Kandidaten skal kartleggja sitt eige utbyte og setja det i samanheng. Det ser ikkje ut som om det har vore enklare enn å ta ein skriftleg eksamen. Mange har sett at A, der dei må overraska (positivt), låg utanfor rekkjevidd. Totalt 156 kandidatar leverte mappe. Det er klart at mappa ikkje fortel oss om studentane kan rekna sjølv, men det er heller ingenting som tyder på at dei har kopiert andre. Der er stor variasjon i format, oppgåvevalg, løysingsformat og refleksjonar. Denne originaliteten vitnar om mange kandidatar som har gjort dei matematiske metodane til sine eigne, og sett dei ein samanheng som er nyttig for dei. Det er vanskeleg å tru at desse kandidatane ikkje har det grunnlaget som dei treng for å delta aktivt i faglege diskusjonar, med matematikk som verkty, $\mathrm{i}$ framtida.

Presentasjon og argumentasjon er derimot ikkje vorte nemneverdig betre enn på tidlegare eksamenar. Få studentar forklarer kvifor dei vel den formelen som dei vel, og enno færre forklarer korleis kvar verdi i formelen er vald. Sannsynlegvis treng me òg her ein tydelegare instruks, t.d. at ein alltid skal svara på,

1. kvifor og korleis representerer formelen (eller modellen) det praktiske problemet?

2. korleis veit du at svaret ditt er rett?

Hittil har instruksen vore formulert som at ein skal overtyda lesaren om at svaret er rett. Håpet har vore at dei gjennom gruppearbeidet vil sjå kva dei treng for å overtyda kvarandre. Dette er tydelegvis ikkje nok, når dei kjem til mappa.

Betre formativ vurdering er truleg ein kritisk komponent til vidare forbetring. Når studentane skal kopiera reine prosedyreferdigheiter, kan det vera nok å forklara dei. Det danningsinnhaldet som trengst for forståing kan ein derimot berre formidla i direkte møte mellom menneske (Kemp, 2013), og studentane sine forsøk må vera tema i dette møtet. Formativ vurdering er ressurskrevjande, men emnet har allereie to innleveringar av refleksjonsnotat som obligatorisk arbeidskrav. Hittil har dei vore svært frie i formen, der dei skal levera arbeidet frå éi heil rekneøving. Dersom me snevrar dette inn til éin oppgåve, gjerne kompleks og samansett, der dei skal vera nøye med argumentasjon og validering av løysinga, vil det vera mogleg å konsentrera tilbakemeldinga der ho trengst mest.

Vurderinga var svært krevjande, fordi der er mange ulike kriterium som må vektast. M.a. er det uklart kva me meiner med originale oppgåver. Er det nok å byta tal i ei standardoppgåve, eller må det vera ein genuint ny problemtype? Dette vert særleg tydeleg for dei mange kandidatane som dokumenterer alle 
skal-måla, saman med nokon eigne oppgåver som eigentleg viser dei same ferdigheitene. Dette er i stor grad ein barnesjukdom. Basert observasjonar frå det fyrste kullet, vil det vera enklare å formulera tydelegare vurderingskriterium, t.d. i rubrikkformat. Det er eit dilemma, fordi overtydelege vurderingskriterium kan skapa ein mal som studentane kopierer, men det må vera mogleg å verta tydelegare neste gong, og ta med kreativitet og originalitet som eksplisitt positive element.

Mange studentar overvurderer seg sjølv. Dei har arbeidd hardt for å nå dei viktigaste måla som skal rekkja til ein $\mathrm{C}$ og tenkjer då at dei fortener ein $\mathrm{A}$, utan at dei ein gong har sett på bør-måla. Dette er nok òg eit døme på utydeleg informasjon. Dersom temaliste, læringsutbyte og karakterdefinisjon vart revidert i eitt samla dokument, med meir konsekvent taksonomi og inndeling, ville det nok vera enklare for studentane å vurdera sitt eige nivå.

Funksjonsdrøfting framstår stadig som den største utfordringen for mange studentar. Det har me sett både på eksamen 2019 og i mappa 2020. Dei aller fleste er likevel komne i mål, og drøfta ein funksjon på det nivået som me har kravd på eksamen. Nokre få har hoppa over heile dette læringsutbyttet, eller berre levert eit maskinplott, og nokre få har gjort alvorlege feil. Litt fleire har nøydd seg med å drøfta ein andregrafsfunksjon, og dermed vist færre teknikkar, men i alle fall har dei vist at dei er merksame på funksjonsdrøfting som ei vesentleg kompetanse.

Mange studentar nemner i refleksjonen at dei kjenner at mappevurderinga er ein nyttig og rettvis vurderingsform. Den eine negative kommentaren som me har festa oss ved, legg vekt på at éi samla sluttvurdering ikkje er optimalt.

\section{KONKLUSJON}

Ein god vurderingsform er ikkje skapt på eitt semester, og det som me har presentert er difor ikkje ei ferdig løysing. Hovudargumentet vårt for å forlata skriftleg eksamen er at dei ferdigheitene som vert testa ikkje er tilstrekkelege, og kanskje ikkje ein gong naudsynte. Mappeordninga er laga for at studentane skal halda fokuset på dei naudsynte læringsutbyta heile vegen til vurderinga er slutt. Me vonar at eit revidert opplegg neste studieår vert enno betre.

\section{REFERANSAR}

Boaler, Jo (2015). Mathematical mindsets: unleashing students' potential through creative math, inspiring messages, and innovative teaching. Jossey-Bass. ISBN: 978-0-470-89452-1.

Clark, Ruth C, Frank Nguyen og John Sweller (2005). Efficiency in Learning: Evidence-Based Guidelines to Manage Cognitive Load. Pfeiffer, San Francisco.

Holm, Marit (2012). Opplaering i matematikk. Cappelen Damm, s. 144. ISBN: 9788202378851.

Kemp, Peter (2013). Verdensborgeren: paedagogisk og politisk ideal for det 21. århundrede. 2. reviderede udgave. Hans Reitzels Forlag.

Niss, Mogens og Tomas Højgaard (2011). Competencies and Mathematical Learning: Ideas and inspiration for the development of mathematics teaching and learning in Denmark. Tekn. rapp. IMFUFA, Roskilde university.

Piercey, Victor og Erin Militzer (2017). "An inquiry-based quantitative reasoning course for business students”. I: PRIMUS 27.7, s. 693-706.

Rogers, Carl R og H Jerome Freiberg (1994). Freedom to learn. Third. Macmillan College Publishing Company.

Schön, Donald A. (1983). The Reflective Practioner. Ashgate Arena.

- (1987). Educating the reflective practitioner. Jossey-Bass San Francisco.

Schaathun, Hans Georg og Jan Gunnar Moe (mar. 2019). "Kva er eigentleg målet i matematikken?” I: MNT-Konferansen. Red. av Reidar Lyng. Nordic Journal of STEM Education. https : //www . ntnu . no/ojs/index.php/njse/article/view/2992. 